Richard I. Hall MD FRCPC FCCP,* Noel O'Regan BSc, Martin Gardner MD FRCPC†

\title{
Detection of intraoperative myocardial ischaemia - a comparison among electrocardiographic, myocardial metabolic, and haemodynamic measurements in patients with reduced ventricular function
}

This study determined the sensitivity and specificity of haemodynamic and ECG monitors to detect the development of intraoperative myocardial ischaemia utilizing myocardial lactate production as the standard. In 29 patients with reduced ejection fraction (0.27-0.50) undergoing coronary artery revascularization, measurements were made at the awake, post-induction, post-intubation, first skin incision, post-sternotomy, preprotamine, immediately post-cardiopulmonary bypass, and skin suture intervals. At each interval, measurement of a haemodynamic profile (including pulmonary artery occlusion (PAOP)

\section{Key words}

ANAESTHESIA: cardiac;

ISCHAEMIA: myocardial, detection;

MONITORING: perioperative, ECG, myocardial lactate, pressure rate quotient, haemodynamics;

SURGERY: cardiovascular.

From the Departments of Anaesthesia* and Medicinet,

Dalhousie University and the Victoria General Hospital, 1278

Tower Road, Halifax, Nova Scotia, Canada.

Address correspondence to: Dr. Richard 1. Hall, Department of Anaesthesia, Victoria General Hospital, 1278 Tower Road,

Halifax, NS, Canada B3H 2 Y9.

Presented in part at the 50th Annual Meeting of the Canadian Anaesthetists' Society, Halifax, Nova Scotia, June 1993.

Dr. Hall is a PMAC/MRC Health Research Foundation

Career Award Recipient. Supported by: Zeneca Pharma Canada.

Accepted for publication 10th February, 1995. and central venous (CVP) pressures, heart rate, and pressure rate quotient); myocardial lactate extraction and fiux; changes in ST segments in ECG leads, $V_{5}$ and II utilizing a Siemens $1280^{\circ}$ intraoperative monitor, and a Marquette $8500^{\circ}$ Holter monitor utilizing leads $V_{5}, V_{2}$, and $A V F$ were made. "Ischaemia" was considered to be present when myocardial lactate production (MLP) occurred, PAOP or CVP increased by $5 \mathrm{~mm} \mathrm{Hg}$ above the baseline value, the pressure rate quotient was $<1$, or ST segment deviation $(>1 \mathrm{~mm}$ ) occurred in any lead for $>1$ min. Variables positive when MLP was positive were the pressure rate quotient (sensitivity $32.8 \%$, specificity $71.9 \%$ ), CVP (sensitivity 10.9\%, specificity 92.6\%), and PAOP (sensitivity 1.6\%, specificity 99.2\%). Holter monitoring had a $100 \%$ pasitive predictive value but poor sensitivity (1.6\%). The ECG (Lead $\left.V_{5}+I I\right)$ measures of ischaemia were insensitive (17.5\%) and relatively non-specific (87.7\%). We conclude that, in this patient group and using myocardial lactate production as the standard, the pressure rate quotient, elevations in CVP or PAOP, or ST segment changes are insensitive measures of intraoperative myocardial ischaemia.

Cette étude évalue la sensibilité et la spécificité des moniteurs de l'hémodynamique et d'ECG pour détecter le développement per-opératoire de lischémie myocardique en utilisant la production de lactate myocardique (PLM) comme indice de référence. Chez 29 patients avec une fraction d'éjection diminuée $(0,27-0,50)$ soumis à une chirurgie de revascularisation coronaire, les mesures sont réalisées aux intervalles suivants. avant l'anesthésie, après linduction, après lintubation, à l'incision de la peau, après la sternotomie, avant la protamine, 
immédiatement après la CEC et au moment de la suture de la peau. A chaque intervalle, la mesure du profil hémodynamique (la pression capillaire bloquée (PCR), la pression veineuse centrale $(P V C)$, la fréquence cardiaque et le quotient pression-fréquence); l'extraction et le flux du lactate myocardique; les changements du segment $S T$ aux dérivations $V_{5}$ et II de l'ECG sur un moniteur Siemens $1280^{\circledR}$, et avec les dérivations $V_{5}, V_{2}$, et $A V F$ sur un moniteur de Holter Marquette $8500^{\circledR}$. Lüschémie est confirmée quand la production de la $P C M$ se manifeste, la PCB ou la PCV augmente de $5 \mathrm{~mm} \mathrm{Hg}$ au-dessus de la ligne de base, que le quotient pression-fréquence est inférieur à un, ou que la déviation du segment ST $>1$ $\mathrm{mm}$ ) survient dans une des dérivations pendant au moins une minute. Lorsque la PLM est positive, les paramètres positifs sont le quotient pression-fréquence (sensibilité $32,8 \%$, spécificité 71,9\%), la PVC (sensibilité 10,9\%, spécificité 92,6\%), et la CPB (sensibilité 1,6\%, spécificité 99,2\%). Le moniteur de Holter a une valeur prédictive de $100 \%$ mais une sensibilité pauvre (1,6\%). A L'ECG (dérivation $V_{S}$ et II), la mesures de l'schémie manque de sensibilité $(17,5 \%)$ et est relativement non spécifique $(87,7 \%)$. Nous concluons que, dans ce groupe de patients, avec la production de lactate myocardique comme indice de référence, le produit pression-fréquence, les élévations de la PCV ou de la PCB ou les changements du segment ST sont des mesures non sensibles de lischémie myocardique peropératoire.

Perioperative myocardial ischaemia is common in patients undergoing coronary artery bypass graft $(\mathrm{CABG})^{1,2}$ procedures and is a risk factor for the development of postoperative myocardial infarction (PMI). ${ }^{3}$

Early detection of myocardial ischaemia may allow the clinician to intervene before an adverse outcome occurs. There are several indicators of ischaemia which can be utilized for this purpose. These include the ECG changes of ST-segment elevation or depression as seen using intraoperative ECG monitors or a Holter monitor, ${ }^{4,5}$ measurements of the pulmonary artery occlusion (wedge) (PAOP) or central venous (CVP) pressure, ${ }^{6,7}$ measurement of myocardial lactate production, ${ }^{8-13}$ echocardiographic monitoring of segmental wall motion abnormalities $^{14}$ and the use of radioactive isotopes. ${ }^{15}$ The sensitivity and specificity of these indicators for the detection of ischaemia vary depending on what is used as the comparative standard, e.g., transoesophageal echo ${ }^{14,16}$ but the traditional indicator has been changes in the ECG. ${ }^{4}$

Comparative studies determining the sensitivity and specificity of intraoperative haemodynamic, myocardial metabolic and ECG monitors to detect the presence or absence of myocardial ischaemia are few and none have compared these monitors using myocardial lactate production as the "gold standard." Myocardial lactate pro- duction is considered to be a definite indicator of myocardial ischaemia, i.e., highly specific. ${ }^{8-13}$ This study determined the sensitivity and specificity of changes in the CVP or PAOP, pressure rate quotient, ${ }^{17-21}$ ST segment changes as determined using a Siemens Model $1280^{\circledR}$ intraoperative monitor (Leads II and $V_{5}$ ) or a Marquette $8500^{\circledR}$ Holter monitor (Leads $V_{5}, V_{2}$ and AVF) to detect the presence of myocardial ischaemia when myocardial lactate production was measured. A group of patients with impaired ventricular function (EF 0.27-0.50) undergoing coronary artery surgery. and felt to have an increased likelihood of developing intraoperative ischaemia were studied.

\section{Methods}

\section{Patient selection criteria}

Following institutional approval by the Investigational Review Board, all patients gave informed consent to participate in the study. Patients selected were scheduled for elective coronary artery bypass graft (CABG) surgery and had reduced ventricular function. Reduced ventricular function was defined as an ejection fraction $<0.50$ measured using biplane angiography at the time of candiac catheterization. Those requiring emergency surgery or presenting with severe systemic, non-cardiac disease were excluded.

\section{Anaesthetic technique}

Patients $(n=29)$ represent a subset of a larger study $(n=60)$, the details of which are reported elsewhere. ${ }^{13}$ The present report includes only those patients in whom complete data sets for all variables of interest were available. The limiting factor for the majority of cases was availability of the Holter monitor.

Patients received one of three anaesthetic regimens as part of the larger study. In brief, in the first group $(n=9)$, patients received propofol for induction of anaesthesia, a constant rate $\dot{v}$ infusion of sufentanil $0.03 \mu \mathrm{g} \cdot \mathrm{kg}^{-1} \cdot \mathrm{min}^{-1}$ until the onset of cardiopulmonary bypass, and a variable rate infusion of propofol 50-200 $\mu \mathrm{g} \cdot \mathrm{kg}^{-1} \cdot \mathrm{min}^{-1}$ in response to surgical stimulation. $\mathrm{Pa}-$ tients in the second group $(n=11)$ received sufentanil up to $5 \mu \mathrm{g} \cdot \mathrm{kg}^{-1} \dot{\tau} \nu$ for induction of anaesthesia, and a variable rate propofol infusion at $50-200 \mu \mathrm{g} \cdot \mathrm{kg}^{-1}$ titrated to clinical response. The third group $(n=9)$ received sufentanil $5 \mu \mathrm{g} \cdot \mathrm{kg}^{-1}$ for induction of anaesthesia which was maintained by the use of enflurane (maximum $3 \%$ inspired at an oxygen flow rate of $4 \mathrm{~L} \cdot \mathrm{min}^{-1}$ ).

\section{Conduct of cardiopulmonary bypass (CPB)}

A crystalloid priming solution, bubble or membrane oxygenator, an in-line arterial filter, and flow rates of 
$2.5 \mathrm{~L} \cdot \mathrm{min}^{-1} \cdot \mathrm{m}^{-2}$ with hypothermia to $25-28^{\circ} \mathrm{C}$ or normothermia $35-37^{\circ} \mathrm{C}$ was employed. Mean arterial pressure of $50-70 \mathrm{mmHg}$ was maintained. Blood gases were maintained using a temperature uncorrected technique.

\section{Haemodynamic and metabolic measurements}

Haemodynamic and myocardial metabolic measurements were made at: (1) control (awake, sedated); (2) postinduction; (3) post-intubation; (4) first skin incision; (5) post-sternotomy; (6) pre-protamine; (7) immediately postcardiopulmonary bypass; and (8) skin suture intervals. The position of the coronary sinus catheter was confirmed by radiological examination before induction of anaesthesia ${ }^{13}$ and by digital palpation by the surgeon following termination of CPB. Measurements included: (1) cardiac output (Siemens Model VG: 404-1 thermodilution device with two values replicated within $10 \%$ of each other); (2) pulmonary artery occlusion pressure using an Abbott Multiflex $\mathrm{TD}^{\circledR}$ thermodilution pulmonary artery catheter Model No. 41223-01 (Abbott Critical Care Systems, Chicago, Illinois); (3) coronary sinus blood flow using a thermodilution Baim ${ }^{\circledR}$ coronary sinus catheter, Baim ${ }^{\circledR}$ coronary sinus flow catheter Model No. 75-2337 (Brent Surgical Supplies, Toronto, Canada); (4) systemic arterial and coronary sinus blood gases and lactate levels (Yellow Springs Lactate Analyzer ${ }^{\circledR}$ ). Derived indices included the cardiac index, systemic and pulmonary vascular resistance index, myocardial lactate extraction and flux, left ventricular stroke work index, and myocardial oxygen consumption utilizing standard formulae. ${ }^{22}$ The pressure rate quotient (mean arterial pressure/heart rate (normal value $>1$ )) was derived from the requisite measurement variables.

A calibrated four-channel strip chart (Siemens Model SIREDOC ${ }^{\circledR}$ ) continuously recorded the systemic arterial, pulmonary arterial, and CVP until the onset of cardiopulmonary bypass. The mean systemic arterial pressure was recorded at ten-minute intervals during cardiopulmonary bypass. Following termination of cardiopulmonary bypass, recording of systemic, central venous, and pulmonary arterial pressures resumed.

The ST-segments were measured from Leads $\mathrm{V}_{5}$ and II on the strip chart (calibration signal 1 mvolts $=10$ $\mathrm{mm}$ ) from the OR monitor (Siemens Model $1280^{\circledR}$ ) recorded at $25 \mathrm{~mm} / \mathrm{sec}$ at each of the measurement points. The band width filter was set at $0.5-40 \mathrm{~Hz}$, i.e., "monitor" mode. The ST-segment deviation was measured at 60 msec after the $J$ point using the control measure as the baseline. An ischaemic episode was defined as $\geq 1 \mathrm{~mm}$ deviation in any direction from the baseline measurement for more than one minute.

A Marquette ${ }^{\circledast} 8500$ Holter monitor (calibration signal $1 \mathrm{mV}=10 \mathrm{~mm}$ ) with a recording frequency between
0.05 and $100 \mathrm{~Hz}$ was placed on subjects approximately $24 \mathrm{hrs}$ before surgery. The lead systems monitored were $\mathrm{V}_{5}, \mathrm{~V}_{2}$, and AVF. Using an electronic scanner, the tapes were read by a cardiologist (MG) blinded to the results of the other measurement points as described above. Ischaemia was considered to be present when ST segment elevation or depression of $1 \mathrm{~mm}$ occurred when measured $60 \mathrm{msec}$ beyond the $J$ point compared with the baseline measurement for more than one minute.

\section{Definition of ischaemia}

Ischaemia was considered to be present whenever myocardial lactate production (i.e., arterial lactate concentration-coronary sinus lactate concentration was $\leq 0$ ) occurred. For comparison, ischaemia detected in the other monitors was defined as an increase in the PAOP or CVP of $5 \mathrm{mmHg}$ above the baseline value, ST segment deviation as defined above measured in any lead of the ECG or Holter, or if the pressure rate quotient was outside the normal range. The use of a $5 \mathrm{mmHg}$ rise in the CVP or PAOP as a measure of the presence of ischaemia was chosen arbitrarily. We are unaware of data which define ischaemia in this context to guide us with this definition. We believed that, at least on clinical grounds, such an increase would alert the clinician to the possibility that myocardial ischaemia was occurring. All episodes of ischaemia detected clinically were treated by altering the anaesthetic level and/or by the use of nitroglycerin (e.g., ST segment changes unrelated to haemodynamic changes) as appropriate. All measurements were made within the five-minute interval following the stimulus to allow for change due to the stimulus to occur and the detection of that change in the variable of interest.

\section{Statistical analysis}

The sensitivity, specificity, positive predictive value, and negative predictive value (see Appendix for definition) for the incidence of ischaemia compared with the presence or absence of myocardial lactate production was calculated for each of the monitors of ischaemia. McNemar's test determined differences between variables with $P<0.05$ taken as a statistically significant result.

\section{Results}

There were no between-group differences with respect to the incidence of perioperative ischaemia. Data for all groups were therefore pooled. Twenty-two of 29 patients had an ischaemic episode at some point during their intraoperative course. Of 185 evaluable data points, myocardial lactate production occurred in 63 episodes of monitoring (34.1\% incidence). Table I provides details of the distribution of ischaemic events as detected by myocardial lactate production at each of the measurement points. 
TABLE I Distribution of ischaemic events as detected by myocardial lactate production at each of the intraoperative measurement points

\begin{tabular}{lcc}
\hline & \multicolumn{2}{c}{ Ischaemia } \\
\cline { 2 - 3 } \cline { 2 - 3 } Measurement point time & Yes & No \\
\hline Awake, sedated & 8 & 19 \\
Post-induction & 5 & 20 \\
Post-intubation & 9 & 18 \\
First skin incision & 12 & 14 \\
Post-sternotomy & 8 & 15 \\
Pre-protamine & 11 & 14 \\
Immediately post-CPB & 6 & 11 \\
Skin suture & 4 & $\underline{11}$ \\
Total & 63 & 122 \\
\hline
\end{tabular}

Of the 29 patients used for data acquisition, the majority were men $(27 / 29)$ with a mean age of $57 \mathrm{yr}$ (range 46-73 yr). This population had a mean ejection fraction (EF) of $41 \%$ (range $27-50$ ) with a mean left ventricular end diastolic pressure (LVEDP) of 17 (range 6-32). Several patients had previous MIs (4/29) and typical risk factors for heart disease were prevalent (diabetes mellitus 27/29; hypercholesterolaemia 17/29; hypertension 14/29; and history of tobacco use 13/29). Further demographic information is provided in Table II.

Data for sensitivity and specificity using myocardial lactate production as the "Gold Standard" are presented in Table III. The sensitivity of the remaining indicators of ischaemia was poor. The pressure rate quotient was the most sensitive at only $32.8 \%$ but lacked specificity (71.9\%) and had a poor positive predictive value. Holter monitoring was insensitive (1.6\%) but specific (100\%) and had the highest positive predictive value (Table III, Figures 1 and 2). The concurrence rate, i.e., rate at which myocardial lactate production occurred and ischaemia was determined to be present by at least one other monitor at the same time is given in Table IV.

\section{Discussion}

A variety of modalities has been used to detect intraoperative myocardial ischaemia including changes in the ECG, ${ }^{2,4,5}$ haemodynamic variables, ${ }^{6,7}$ transoesophageal echocardiography ${ }^{14,16}$ and myocardial metabolic indices. ${ }^{8,9,13}$ Few studies have compared the sensitivity and specificity of monitors designed to detect intraoperative myocardial ischaemia. Using myocardial lactate production as the standard for the detection of ischaemia in this study, the pressure rate quotient was determined to be the most sensitive (32.8\%) measure of ischaemia but lacked specificity (71.9\%). Holter monitoring showed a $100 \%$ positive predictive value but lacked sensitivity to detect ischaemia (1.6\%). All other monitors showed poor sensitivity $(<30 \%)$, but reasonably good specificity
TABLE II Demographic data for patients with impaired left ventricular function (ejection fraction between 27 and 50\%) having coronary artery bypass graft surgery

\begin{tabular}{ll}
\hline History & $n /$ Total \\
ASA III & $27 / 29$ \\
ASA IV & $2 / 29$ \\
I Vessel disease & $0 / 29$ \\
2 Vessel disease & $5 / 29$ \\
3 Vessel disease & $24 / 29$ \\
& \\
Intraoperative course & Mean (SD) \\
Duration of anaesthesia (min) & $241(61)$ \\
Duration of bypass (min) & $98(48)$ \\
Mean pump flow (L· $\left.\min ^{-1} \cdot \mathrm{m}^{-2}\right)$ & $2.5(0.1)$ \\
Cross clamp time (min) & $50(24)$ \\
Number of grafts received & $3(1)$ \\
& \\
& $n /$ Total \\
Number undergoing hypothermic bypass & $1 / 29$ \\
Number of patients receiving IMA grafts & $26 / 29$ \\
Number of patients requiring inotropes & $11 / 29$ \\
\hline
\end{tabular}

$(>73 \%)$, and poor positive $(<45 \%)$, and negative predictive values (approximately 65\%) (Table III).

\section{Limitations on the use of myocardial lactate as a gold standard}

Myocardial lactate production can be utilized as a method for indicating myocardial ischaemia during cardiac surgery since myocardial lactate is an end production of anaerobic metabolism. ${ }^{10-12}$ Measuring myocardial lactate extraction from arterial and coronary sinus blood samples is possible intraoperatively and production of myocardial lactate is an indicator of myocardial ischaemia since the heart ordinarily extracts lactate as a part of aerobic metabolism. ${ }^{10-12}$ The method suffers from the fact that regional myocardial ischaemia may still be present (particularly right ventricular ischaemia) in the face of global lactate extraction. " Placement of a coronary sinus catheter is a highly invasive procedure, and there is a delay between when the measurement is taken and the result is reported.

During cardiac surgery, arterial lactate concentrations may rise due to abnormalities in tissue perfusion and liver metabolism. This increase may mask local lactate production in the heart. However, we were able to measure myocardial lactate production in at least some of the patients in whom it occurred in the immediate post-CPB period (Table I) suggesting that the method has utility for measuring ischaemia even under these circumstances.

\section{Comparative studies}

Haggmark et al. ${ }^{23}$ compared myocardial lactate production with changes in segmental wall motion as determined by a cardiokymogram or ST segment changes on the 
TABLE III Sensitivity, specificity, positive predictive value and negative predictive value of ischaemic indicators compared with myocardial lactate production

\begin{tabular}{lcccc}
\hline Variable & $\begin{array}{l}\text { Sensitivity } \\
(\%)\end{array}$ & $\begin{array}{l}\text { Specificity } \\
(\%)\end{array}$ & $\begin{array}{l}\text { +Pred val* } \\
(\%)\end{array}$ & $\begin{array}{l}\text {-Pred valt } \\
(\%)\end{array}$ \\
\hline Pressure rate quotient & 32.8 & 71.9 & 38.2 & 66.9 \\
Central venous pressure & 10.9 & 92.6 & 43.7 & 66.3 \\
Pulmonary artery occlusion pressure & 1.6 & 99.2 & 12.5 & 64.4 \\
Holter monitor ECG & 1.6 & 100.0 & 100.0 & 65.8 \\
Strip chart ECG chest lead & 11.1 & 78.7 & 21.2 & 63.2 \\
Strip chart ECG lead II & 25.4 & 73.8 & 33.3 & 65.7 \\
Strip chart II + V & 17.5 & 87.7 & 42.3 & 67.3 \\
\hline
\end{tabular}

*Positive predictive value.

$\dagger$ Negative predictive value.

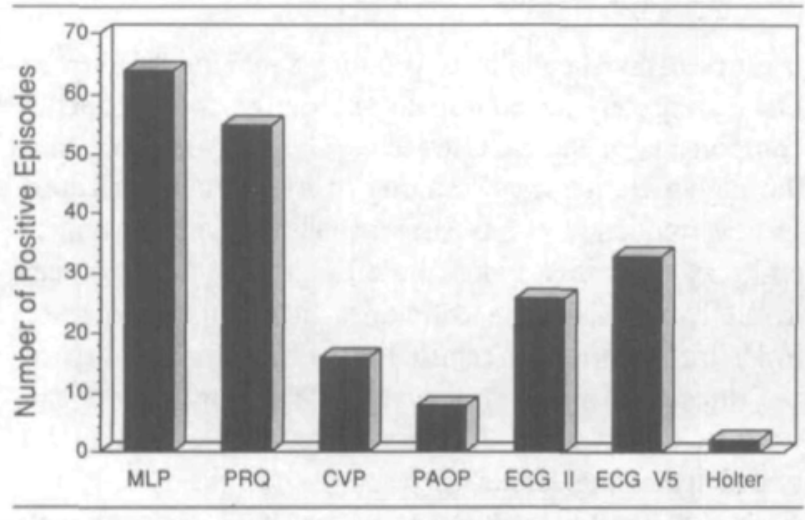

FIGURE 1 Number of episodes where ischaemia was detected as present for each of the intraoperative monitors. MLP $=$ myocandial lactate production; $\mathrm{PRQ}=$ pressure rate quotient; $\mathrm{CVP}=$ central venous pressure; $\mathrm{PAOP}=$ pulmonary artery occlusion pressure; $\mathrm{ECG}$ $\mathrm{Il}=$ electrocardiogram lead II from a Siemens Model 1280' intraoperative monitor, ECG $V_{5}=$ electrocardiogram lead $V_{5}$ from a Siemens Model 1280 intraoperative monitor, Holter $=$ Marquette Model 8500 Holter@ monitor.

ECG as indicating myocardial ischaemia. Myocardial lactate production was the least sensitive indicator of ischaemia. However, six of eight patients with myocardial lactate production present before induction of anaesthesia were excluded from subsequent analysis (vs two with wall motion abnormalities alone or three with both wall motion and myocardial lactate production) which may have biased the data against myocardial lactate production as a sensitive indicator of ischaemia. Of the remaining 53 patients studied, ischaemia (as measured by changes on the cardiokymogram, elevations in the pulmonary artery occlusion pressure, myocardial lactate production, or changes on the surface ECG) occurred in 39 (74\%). The majority of episodes were diagnosed by the cardiokymogram (74 of 89 episodes) while the ECG (31 of 89) and myocardial lactate production (13 of 89 ) were less sensitive. The role of motion artifact in creating false pos-

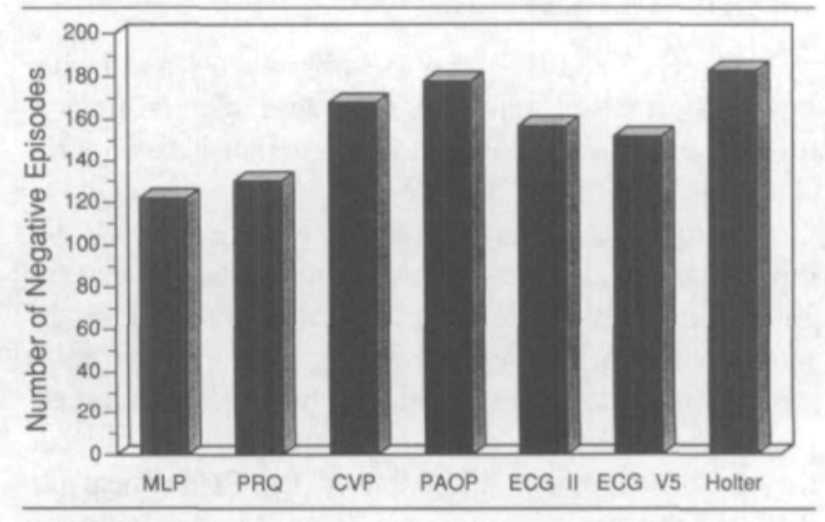

FIGURE 2 Number of episodes where ischaemia was not detected as present for each of the intraoperative monitors. MLP $=$ myocardial lactate production; $\mathrm{PRQ}=$ pressure rate quotient; $\mathrm{CVP}=$ central venous pressure; $\mathrm{PAOP}=$ pulmonary artery occlusion pressure; $E C G$ II = electrocardiogram lead II from a Siemens Model $1280^{\circ}$ intraoperative monitor, $E C G V_{5}=$ electrocardiogram lead $V_{5}$ from a Siemens Model $1280^{\circledR}$ intraoperative monitor, Holter $=$ Marquette Model $8500^{\circledR}$ Holter monitor.

itive images of wall motion abnormalities was not discussed. These authors found measurement of changes in the PAOP to be of little additional benefit in diagnosing ischaemia - a finding which is supported by the data in the present study.

There has been some controversy as to whether the pressure rate quotient (PRQ) compared with the ECG or transoesophageal echocardiogram (TEE) is an effective indicator of the development of intraoperative myocardial ischaemia. ${ }^{17-20}$ Harris et al. ${ }^{18}$ compared the PRQ with transoesophageal echocardiography (TEE) and ECG and found the PRQ to have a sensitivity of only $18 \%$ and positive predictive value of $16 \%$ relative to the ECG. Similar conclusions of poor sensitivity and positive predictive value were reached by Gordon et al. ${ }^{19}$ In our study TEE was not available. While the sensitivity of the $P R Q$ was higher than that of the ECG to detect ischaemia (PRQ 
TABLE IV Concurrence rate among variables utilized for detection of myocardial ischaemia when myocandial lactate production was positive, i.e., ischaemia was present. Myocardial lactate production was measured in 63 of 185 measurement points

\begin{tabular}{lcccccccc}
\hline Variable & Mlprod & $P R Q$ & $C V P$ & PAOP & Holter & $V_{5}$ & $I I$ & $V_{5}+I I$ \\
\hline MLPROD & 63 & 20 & $7^{*}$ & $1^{*}$ & $1^{*}$ & $7^{*}$ & $11^{*}$ & 16 \\
PRQ & 20 & 55 & $6^{*}$ & $3^{*}$ & $1^{*}$ & $13^{*}$ & $6^{*}$ & 15 \\
CVP & $7^{*}$ & $6^{*}$ & 16 & 1 & $0^{*}$ & $2^{*}$ & 0 & $2^{*}$ \\
PAOP & $1^{*}$ & $3^{*}$ & 1 & 8 & $0^{*}$ & $3^{*}$ & $0^{*}$ & $3^{*}$ \\
Holter & $1^{*}$ & $1^{*}$ & $0^{*}$ & $0^{*}$ & 1 & $0^{*}$ & $0^{*}$ & $0^{*}$ \\
$V_{5}$ & $7^{*}$ & $13^{*}$ & $2^{*}$ & $3^{*}$ & $0^{*}$ & 33 & 11 & $33^{*}$ \\
II & $11^{*}$ & $6^{*}$ & 0 & $0^{*}$ & $0^{*}$ & 11 & 26 & $26^{*}$ \\
$V_{5}+$ II & 16 & 15 & $2^{*}$ & $3^{*}$ & $0^{*}$ & $33^{*}$ & $26^{*}$ & 48 \\
\hline
\end{tabular}

$* P<0.05$ vs variable in column 1 .

MLPROD = myocardial lactate production; $P R Q=$ pressure rate quotient; $C V P=$ central venous pressure;

PAOP = pulmonary artery occlusion pressure; Holter $=$ Holter monitor (leads $\left.V_{5}, V_{2}, A V F\right) ; V_{5}=O R$ monitor lead V5; II = OR monitor lead II.

$=32.8 \%$; ST Lead II $=25.4 \%$; ST V $\mathrm{V}_{5}=1.6 \%$ and Holter $=11.1 \%$ ), it is still much less than desirable and its positive predictive value (38.2\%) suggests that it has limited clinical utility.

Although we employed leads felt to be sensitive for the detection of ischaemia, ${ }^{5}$ our findings suggest that the ECG is an insensitive standard for the detection of ischaemia. Kleinman also determined that the ECG is not a sensitive indicator of myocardial ischaemia. ${ }^{15}$ Several explanations have been proposed, some of which include the use of $0.1 \mathrm{mV}$ as the criterion for ST segment deviation, ${ }^{4}$ the use of only leads $\mathrm{II}$ and $\mathrm{V}_{5}$ for detection of ischaemia (events may occur in areas which are not detected by these leads, i.e., inferior wall or septal area), ${ }^{15}$ and the difficulty of detecting ischaemia in the presence of conduction deficits. ${ }^{16}$ In light of these issues and the introduction of new technologies to detect ischaemia (e.g., TEE ${ }^{14,16}$ ), the use of the ECG as a gold standard for ischaemia detection requires careful scrutiny. While the ECG was shown to have poor sensitivity for the detection of ischaemia, it was specific (87.7\%) Studies comparing the sensitivity and specificity of TEE vs other modalities for detecting ischaemia including the ECG and myocardial lactate production are needed.

Although a sensitive indicator of ischaemia in awake humans, ${ }^{24,25}$ Holter monitoring for the detection of ischaemia occurring during cardiovascular surgery has been found to be a relatively insensitive indicator of ischaemia. ${ }^{4}$ In this study, Holter monitoring produced a sensitivity of only $1.6 \%$. It was, however, very specific with a high positive predictive value (100\%) suggesting that if ischaemia were detected by Holter monitoring it was likely to be present. Explanations as to why Holter monitoring may fail to detect ischaemia during surgery include the presence of artifact. ${ }^{26,27}$ The component sine waves which produce an ECG trace must be amplified equally and all components passing through recording equipment must be delayed equally, to produce a reliable ECG trace. Depending on the equipment used, the low frequency components of the ECG trace can be delayed more than the higher frequencies resulting in inaccurate replication of low frequency events such as ST segment placement and may generate an inaccurate ECG. This "shift" is seen in all ECG recording techniques but is most common in Holter monitoring because the shift is introduced twice, i.e., during recording and playback. Electronic noise (e.g., use of electrocautery during surgery) may also alter the sensitivity of the Holter to detect ischaemia. Our results suggest that studies relying solely on ECG measurements for detection of ischaemia may seriously underestimate the true incidence of ischaemia. However, if detected by ECG changes, ischaemia is likely to be present.

Previous studies in awake patients have shown a rise in left ventricular end diastolic pressure (LVEDP) with ischaemia. ${ }^{28-30}$ In anaesthetized patients and using PAOP as a surrogate for LVEDP, Kaplan and Wells ${ }^{6}$ and van Daele et al. ${ }^{7}$ determined that an increase in PAOP occurred with ischaemia, but in the study by van Daele et al. it was neither consistent nor reliable. The relationship between onset of ischaemia and changes in PAOP using TEE as the standard for ischaemia detection was determined. They concluded that even though large changes in PAOP can be invaluable in clinical practice, e.g., in the diagnosis of valvular insufficiency, a change in mean PAOP was neither sensitive nor reliable for indicating early myocardial ischaemia. The data from this study of patients with reduced ventricular function and that of Haggmark et al. ${ }^{23}$ support the results obtained by van Daele et al. PAOP was found to be an insensitive indicator of ischaemia (1.6\%). The poor sensitivity of PAOP may be influenced by non-cardiac factors such as fluid therapy, blood loss, and surgical stimulation.

Studies on the utility of CVP measurement have focused mainly on cardiac function rather than on cardiac 
ischaemia. Curiously, in this study, while the CVP proved to be an insensitive indicator of ischaemia (10.9\%), it was more sensitive than the PAOP. This may be related to the definition of ischaemia we imposed for these measurements (i.e., $5 \mathrm{mmHg}$ increase from baseline). The CVP may be more responsive to interventions such as fluid replacement than the PAOP thus giving more false positive readings or alternatively the right ventricle under the conditions of this study was more frequently ischaemic than the left ventricle giving more true positive results. The real incidence of right ventricular ischaemia may be underestimated by measurement of myocardial lactate production. ${ }^{8}$

We are not advocating substituting myocardial lactate measurement as the "gold standard" for measurement of the development of myocardial ischaemia. Rather it was used in this study to examine the inadequacies of other measurement tools currently employed. There is much room for improvement in our ability to assess the development of intraoperative myocardial ischaemia.

We caution that the results of this study were obtained from a selected group of patients - those with impaired ventricular function undergoing cardiac surgery. Whether the results apply to a more general surgical population requires further study.

In conclusion, when using myocardial lactate production as the best measure for detecting intraoperative development of myocardial ischaemia, we have shown that other indicators such as haemodynamic changes and ST segment changes lack sensitivity in a patient population at risk for the development of intraoperative myocardial ischaemia. The ECG was not a sensitive indicator of ischaemia but had a high specificity and positive predictive value. Thus, if the ECG detects ischaemia, it is likely to be present and should be treated. However, the sensitivity of our monitors for the detection of intraoperative myocardial ischaemia leaves a lot to be desired. Use of the ECG as a "gold standard" for measurement of perioperative myocardial ischaemia requires re-evaluation.

\section{Appendix A}

Definitions and equation used for sensitivity, specificity, positive predictive value and negative predictive value.

\begin{tabular}{|c|c|c|}
\hline \multirow[b]{2}{*}{ Indicator } & \multicolumn{2}{|l|}{ Gold standard } \\
\hline & Ischaemic & Non-Ischaemic \\
\hline Positive & $\begin{array}{l}a=\text { number of study peri- } \\
\text { ods with ischaemia and } \\
\text { positive. }\end{array}$ & $\begin{array}{l}\text { b = number of study peri- } \\
\text { ods without ischaemia } \\
\text { and positive. }\end{array}$ \\
\hline Negative & $\begin{array}{l}\mathrm{c}=\text { number of study peri- } \\
\text { ods with ischaemia and } \\
\text { negative. }\end{array}$ & $\begin{array}{l}d=\text { number of study peri- } \\
\text { ods without ischaemia } \\
\text { and negative. }\end{array}$ \\
\hline
\end{tabular}

Sensitivity

Measures the proportion of study periods where ischaemia was present and correctly identified by the indicator.

$$
\text { Sensitivity }=\frac{a}{a+c}
$$

\section{Specificity}

Measures the proportion of study periods without ischaemia and is correctly labelled as negative by the indicator.

Specificity $=\frac{d}{b+d}$

\section{Positive predictive value}

Measures the proportion of study periods with a positive indication when there actually is ischaemia present.

Positive predictive value $=\frac{a}{a+b}$

\section{Negative predictive value}

Measures the proportion of study periods with a negative indication when there actually is not ischaemia present.

Negative predictive value $=\frac{d}{c+d}$

\section{Reference}

Riegelman and Hirsch. Studying a Study and Testing a Test. Little, Brown and Company. Boston, Toronto and London, 1989. Chapter 17, Diagnostic Discrimination of Tests.

\section{References}

1 Mangano DT and the Study of Perioperative Ischemia (SPI) Research Group. Characteristics of electrocardiographic ischaemia in high-risk patients undergoing surgery. J Electrocardiol 1990; 23 (Suppl.): $20-7$.

2 Knight AA, Hollenberg M, London MJ, et al. Perioperative myocardial ischemia: importance of the preoperative ischemic pattern. Anesthesiology 1988; 68: 681-8.

3 Slogoff S, Keats AS. Does perioperative myocardial ischemia lead to postoperative myocardial infarction? Anesthesiology 1985; 62: 107-14.

4 Slogoff S, Keats AS, David Y, Igo SR. Incidence of perioperative myocardial ischemia detected by different electrocardiographic systems. Anesthesiology 1990; 73: 1074-81.

5 London MJ, Hollenberg $M$, Wong $M G$, et al. Intraoperative myocardial ischemia: localization by continuous 
12-lead electrocardiography. Anesthesiology 1988; 69: 232-41.

6 Kaplan JA, Wells PH. Early diagnosis of myocardial ischemia using the pulmonary arterial catheter. Anesth Analg 1981; 60: 789-93.

7 van Daele MERM, Sutherland GR, Mitchell MM, et al. Do changes in pulmonary capillary wedge pressure adequately reflect myocardial ischemia during anesthesia? Circulation 1990; 81: 865-71.

8 Hall RI, Moffitt EA. Monitoring the coronary circulation. Anesthesiology Clinics of North America 1988; 6: 839-50.

9 Hall RI, Moffit EA. The effects of anaesthetics on coronary artery blood flow and myocardial metabolism: a review of studies in animals and man. Ballières Clinical Anaesthesiology 1989; 3: 27-46.

10 Kugler $G$. Myocardial release of lactate, inosine and hypoxanthine during atrial pacing and exercise-induced angina. Circulation 1979; 59: 43-9.

11 Opie LH, Owen P, Thomas M, Samson R. Coronary sinus lactate measurements in assessment of myocardial ischemia. Am J Cardiol 1973; 32: 295-305.

12 Ferrari $R$, Bolognesi $O$, Raddino $R$. Reproducibility of metabolic parameters during successive coronary sinus pacing in patients known to have coronary artery disease. Int $\mathrm{J}$ Cardiol 1985; 231-4.

13 Hall RI, Murphy JT, Landymore R, Pollack PT, Doak G, Murray $M$. Myocardial metabolic and hemodynamic changes during propofol anesthesia for cardiac surgery in patients with reduced ventricular function. Anesth Analg 1993; 77: 680-9.

14 Leung JM, O'Kelly B, Browner $S$, et al. Prognostic importance of postbypass regional wall-motion abnormalities in patients undergoing coronary artery bypass graft surgery. Anesthesiology 1989; 71: 16-25.

15 Kleinman B, Henkin RE, Glisson SN, et al. Qualitative evaluation of coronary flow during anesthetic induction using thallium-201 perfusion scans. Anesthesiology 1986; 64: 157-64.

16 Smith JS, Cahalan $M K$, Benefiel DJ, et al. Intraoperative detection of myocardial ischemia in high-risk patients: electrocardiography versus two-dimensional transesophageal echocardiography. Circulation 1985; 72: 1015-21.

17 Buffington $C W$. Pressure-rate quotient in patients undergoing coronary artery bypass graft surgery (Letter). Anesthesiology 1991; 75: 710-1.

18 Harris $S N$, Gordon $M A$, Urban $M K$, O'Connor $T Z, B a-$ rash $P G$. The pressure rate quotient is not an indicator of myocardial ischemia in humans. Anesthesiology 1993; 78: 242-50.

19 Gordon $M A$, Urban $M K, O^{\prime}$ Connor T, Barash PG. Is the pressure rate quotient a predictor of myocardial ischemia as measured by ST-segment changes in patients undergoing coronary artery bypass surgery? Anesthesiology 1991; 74: 848-53.

$20 \mathrm{Boba} A$. On the pressure-rate quotient (Letter). Anesthesiology 1992; 76: 858.

21 Buffington $C W$. Hemodynamic determinants of ischemic myocardial dysfunction in the presence of coronary stenosis in dogs. Anesthesiology 1985; 63: 651-62.

22 Moffitt EA, McIntyre AJ, Barker RA, et al. Myocandial metabolism and hemodynamic responses with fentanylenflurane anesthesia for coronary arterial surgery. Anesth Analg 1986; 65: 46-52.

23 Häggmark S, Hohner P, Östman M, et al. Comparison of hemodynamic, electrocardiographic, mechanical, and metabolic indicators of intraoperative myocardial ischemia in vascular surgical patients with coronary artery disease. Anesthesiology 1989; 70: 19-25.

24 Deanfield JE, Shea $M$, Ribiero P, et al. Transient STsegment depression as a marker of myocardial ischemia during daily life. Am J Cardiol 1984; 54: 1195-200.

25 Deanfield JE, Ribiero P, Oakley K, Krikler S, Selwyn AP. Analysis of ST-segment changes in normal subjects: implications for ambulatory monitoring in angina pectoris. Am J Cardiol 1984; 54: 1321-5.

26 Bragg-Remschel DA, Anderson CM, Winkle RA. Frequency response characteristics of ambulatory ECG monitoring systems and their implications for ST segment analysis. Am Heart J 1982; 103: 20-31.

27 Taylor DI, Vincent $R$. Artefactual ST segment abnormalities due to electrocardiograph design. Br Heart J 1985; 54: 121-8.

28 Mann T, Goldberg S, Mudge GH Jr, Grassman W. Factors contributing to altered left ventricle diastolic properties during angina pectoris. Circulation 1979; 59: 14-20.

29 Mann T, Brodie BR, Grassman W, McLaurin LP. Effect of angina on the left ventricular diastolic pressure-volume relationship. Circulation 1977; 55: 761-6.

30 Levy RD, Shapiro LM, Wright C, Mockus LJ, Fox KM. The haemodynamic significance of asymptomatic ST segment depression assessed by ambulatory pulmonary artery pressure monitoring. Br Heart J 1986; 56: 526-30. 